\title{
Thinking Styles and Academic Achievement Among Filipino Students
}

\author{
ALLAN B. I. BERNARDO \\ College of Education \\ De La Salle University, Manila, Philippines \\ LI-FANG ZHANG \\ Department of Education \\ The University of Hong Kong \\ CARMELO M. CALLUENG \\ College of Liberal Arts \\ De La Salle University, Manila, Philippines
}

\begin{abstract}
The authors' objective in this study was to determine whether the precepts of R. J. Sternberg's $(1988,1997)$ theory of mental self-government apply to a non-Western culture. They administered R. J. Sternberg and R. K. Wagner's (1992) Thinking Styles Inventory, which is based on the theory of mental self-government, to 429 Filipino university students. The results of item analysis, scale intercorrelations, and factor analysis were consistent with the general provisions of the theory. Correlational analysis between thinking styles and grade point average showed that thinking styles are related to academic achievement. The results are explained with respect to the concepts and practices of Philippine culture and schools and discussed in relation to the developmental assumptions of the theory of mental self-government.
\end{abstract}

Key words: academic achievement, culture, psychological tests, thinking styles

IN RECENT YEARS, researchers have become more interested in exploring the effects of noncognitive individual-difference variables on academic achievement. These variables, which are not ability variables, include academic self-concept (Helmke \& van Aken, 1995; Marsh \& Yeung, 1997), self-efficacy (Pajares, 1996; Schunk, 1991; Zimmerman, 1995), and motivation and approach to learning (Biggs, 1991; Pintrich \& de Groot, 1990). Studies of these nonability variables have involved Western as well as non-Western, Asian students (Biggs, 1989, 1991; Kwok \& Lytton, 1996; Watkins, 1996).

One individual-difference variable, style, has received particular attention. Styles are not abilities but refer to individuals' preferred way of applying their abilities in cognitive tasks. Some reviewers (Grigorenko \& Sternberg, 1995; Rid- 
ing \& Cheema, 1991) have traced the origin of the construct of style back as far as 1937 (to the work of Allport, 1937); the concept has evolved over time and has taken many different forms (Messick, 1994; Rayner \& Riding, 1997; Riding, 1997; Sternberg \& Grigorenko, 1997). A number of researchers, including those in non-Western countries (Albaili, 1997; Kim \& Michael, 1995), have also investigated the relationship between students' styles and academic achievement; however, their findings have been inconsistent (Dunn, Beaudry, \& Klavas, 1989).

In this article, we report the results of a study relating styles and academic achievement among college students in the Philippines. We assessed styles using the Thinking Styles Inventory (TSI; Sternberg \& Wagner, 1992), which is based on Sternberg's $(1988,1997)$ theory of mental self-government.

\section{Styles and the Theory of Mental Self-Government}

According to Grigorenko and Sternberg (1995; Sternberg \& Grigorenko, 1997), three general approaches are used in defining and assessing styles of thinking and learning. The first approach is cognition centered and deals with cognitive styles. Witken, Oltman, Rasking, and Karp (1971) have succinctly defined these cognitive styles as "the characteristic, self-consistent modes of functioning which individuals show in their perceptual and intellectual abilities" (p. 3). The second approach to studying styles is personality centered and deals with personality traits. The third approach is activity centered and is focused on the notion of "styles as mediators of various forms of activities that may arise from aspects of cognition and personality" (Sternberg \& Grigorenko, 1997, p. 705). Theories pertaining to this third approach tend to focus on styles of teaching and learning.

In his theory of mental self-government, Sternberg $(1988,1997)$ attempts to integrate various approaches to styles. The basic assumption of the theory is that people, like societies, govern themselves and their mental processes and establish systems and organizations for this governance. In the theory, Sternberg provides categories and characterizations of how people organize, direct, and manage their own thinking activities, and he proposes 13 thinking styles, which fall under six aspects of mental self-governance. These 13 styles are briefly

This research was supported by a grant to Allan B. I. Bernardo from the College of Education Research Council, De La Salle University, Manila, and a grant to Li-fang Zhang from the Wu Jieh-Yee Research Fund, The University of Hong Kong. The authors thank Elena Reyes, Denise Mitzi Roman, Hazel Marie Joy Ordenes, Maila Q. Castro, Marvin Reynold Agustin, and Keith Lozada for their assistance in preparing the research materials and in encoding the research data, and the numerous faculty members of De La Salle University for allowing their students to participate in the study. The authors also thank the anonymous reviewers for their helpful comments on earlier drafts of this article.

Address correspondence to Allan B. I. Bernardo, College of Education, De La Salle University, 2401 Taft Avenue, Manila 1004, Philippines; claabb@dlsu.edu.ph (e-mail). 
described in the following sections (for a more detailed discussion, see Sternberg, 1988, 1997).

Functions. Government systems typically have different branches serving various functions; presumably, people also have different styles for focusing on different functions or tasks. There are three functions of people's mental self-government: legislative, executive, and judicial. People who have a legislative style prefer tasks that require using creative strategies and generating new approaches and solutions. People who have an executive style are more concerned with the proper implementation of tasks within a set of guidelines, and those having a judicial style are concerned with evaluating the work process and products of other people's activities.

Levels. In most countries, governance operates at different levels: national, regional, provincial, municipal, and so on. Similarly, in people's mental self-government, in which individuals may vary in terms of their concern for detail, two levels of governance are defined: local and global. People with a local style prefer activities that require them to attend to very specific and concrete details, whereas those with a global style prefer dealing with problems that are general in nature and that require abstract thinking.

Leanings. In governance, political orientations range from the most conservative to the most liberal. These two major leanings, conservative and liberal, are also identified in mental self-government. People with a liberal style prefer tasks that require them to go beyond existing rules and structures and tasks that are aimed at effecting substantial change. Those with a conservative style prefer familiar tasks that require the application of and adherence to existing rules and structures.

Forms. According to Sternberg (1988, 1997), just as there are different forms of government, there are various ways in which individuals govern themselves: monarchic, hierarchic, oligarchic, and anarchic. People with a monarchic style prefer engaging in activities that require them to focus on only one thing at a time. Those with a hierarchic style prefer distributing their attention and energies over several tasks that are prioritized. Those with an oligarchic style prefer working toward several objectives all at the same time without prioritizing the tasks. Finally, individuals with an anarchic style prefer working on tasks that require no system at all, and, thus, allow for greater flexibility.

Scope. Governments typically have both domestic and foreign affairs, which are comparable to the internal and external approaches of mental self-government. Individuals with an internal style prefer tasks that require working independently of other people. In contrast, those with an external style prefer activities that allow for interaction with others. 
According to the theory of mental self-government, people vary in their relative preferences for these styles and may use more than one style as well as flexibly switch from one to another as they adapt to changing task requirements. The stylistic preferences are also viewed as being socialized and as functions of one's interactions within the sociocultural environment.

Sternberg and Grigorenko (1995; Grigorenko \& Sternberg, 1997) conducted research involving American students that demonstrated the usefulness of the theory for understanding achievement and other aspects of students' school performance. For example, in their 1995 study Sternberg and Grigorenko found that students benefited if their thinking styles matched those of their teachers. Students received more positive evaluations and higher grades from teachers having similar styles.

\section{Thinking Styles and Achievement Among Asian Students}

Researchers have conducted some preliminary work in which they applied the mental self-government theory in Asian settings. In particular, Zhang and colleagues (Zhang \& Sachs, 1997; Zhang \& Sternberg, 1998) studied the thinking styles of Chinese college students in Hong Kong. Generally, their findings mirrored those of American researchers and were consistent with predictions of the theory. Nevertheless, there were some differences. In using the TSI (Sternberg \& Wagner, 1992) with Chinese students, for example, Zhang and Sachs (1997) found only three factors in contrast to the five factors that were found by Sternberg (1994), whose study involved American students. Although the difference may have resulted from the rather small sample used in the Hong Kong study, it warrants further exploration. Moreover, additional studies should be conducted to determine the applicability of the mental self-government theory in other Asian settings.

In this study, we explored the utility of the theory of mental self-government among college students in the Philippines. Although the Philippines is Asian, like Hong Kong, the authors of previous studies (see Watkins, 1996) of the two cultures found different patterns of correlations among important personality, learning, and educational achievement variables. For example, most studies with Hong Kong students showed significant correlations between surface approaches to learning and internal locus of control, but studies with Filipino students showed no such correlations. It is reasonable, therefore, to expect differences in terms of how Filipino and Chinese students apply thinking styles, which appear to be products of one's interactions with their environment.

Another aspect of the theory of mental self-government that we sought to explore in this study is whether thinking styles are related to academic achievement, as was found in the Hong Kong and American studies. Because different countries value different types of student behavior and achievement, stress diverse modes of assessment, and encourage different approaches to succeeding in 
school, we anticipated differences in the degree to which thinking styles relate to academic success.

\section{Overview of the Present Study}

Our general objective in this study was to explore the applicability and utility of Sternberg's $(1988,1997)$ theory of mental self-government in a Filipino setting. In particular, we sought to determine the structure of the interrelationships among the 13 thinking styles with a sample of Filipino college students and to verify whether the structure of these interrelationships was consistent with the assumptions and predictions of Sternberg's theory. Moreover, we intended to determine whether thinking styles are predictive of academic success among Filipino students. In our investigation, we administered the short version of the TSI (Sternberg \& Wagner, 1992) to participants and performed a factor analysis. To investigate whether thinking styles predict academic success among Filipino students, we conducted a correlational analysis using the students' TSI scores and grade point average (GPA).

\section{Method}

\section{Participants}

A total of 429 freshman students at De La Salle University, Manila, participated in the study. The sample included 167 men, 256 women, and 6 other students who did not indicate their gender. Their ages ranged from 16 to 21 years (mean age $=17.18$ years; $S D=1.09$ ). The students were enrolled in various undergraduate programs: 153 were enrolled in science and technology, and 239 were enrolled in the humanities, education, and social science programs; 37 students did not indicate their programs of enrollment.

\section{Measures}

To assess students' thinking styles, we used the short version of the TSI (Sternberg \& Wagner, 1992). The TSI is a self-report test with 65 items divided into 13 scales, each containing 5 items that correspond to one of the 13 thinking styles described in Sternberg's theory (1988, 1997; see the Appendix for sample items of the scales). For each item, participants are asked how well the statement describes them, responding to the question on a 7-point Likert-type scale in which 1 indicates that the statement does not describe them at all, and 7 indicates that the statement describes them very well.

In addition to the TSI, we asked participants to complete a subject information sheet concerned with basic demographics, other family information, and educational experiences. Participants were also required to report their cumulative GPA. 


\section{Data Analysis}

After each participant's responses were coded, we calculated item-scale correlations to determine the suitability of items for inclusion in the analysis. Then we estimated the internal consistency of each of the 13 scales using the Cronbach alpha. We performed a factor analysis to determine whether the patterns of responding across the scales were consistent with the assumptions of the theory of mental self-government (Sternberg, 1988, 1997). Finally, the scores from the 13 scales were correlated with the students' reported GPA.

\section{Results}

Item Analysis

Our results revealed three items in the inventory with unacceptably low item-scale correlations; these items were not included in subsequent analysis. The three omitted items were "I prefer to deal with specific problems, rather than with general questions" (Item 1, local, $r=.24$ ); "When talking or writing about ideas, I stick to one main idea" (Item 2, monarchic, $r=.23$ ); and "I tend to pay little attention to details" (Item 7, global, $r=.18$ ). (These same three items were also dropped from the validation study of Zhang \& Sachs, 1997, who used the same short form of the TSI with college students in Hong Kong.) The remaining item-scale correlations ranged from .33 to .82 .

\section{Reliability and Scale Intercorrelations}

We analyzed the internal consistency of the 13 scales (see Table 1). The alpha coefficients ranged from .50 to .81 , with a median of .71. These results are similar to those reported by Sternberg (1994) and by Zhang and Sachs (1997). The intercorrelations among the 13 scales (summarized in Table 2) yielded correlation coefficients with absolute values ranging from .11 to .66, and all were statistically significant at $p<.05$.

\section{Factor Analysis}

The results of the exploratory factor analysis, which was followed by a varimax rotation, are summarized in Table 3 . The factor analysis yielded three factors with eigenvalues larger than those from the random data. These three factors were the only factors retained, and they accounted for $64.3 \%$ of the variance.

For Factor 1, the highest loadings were from the Legislative, Liberal, Internal, Anarchic, Global, and Judicial Scales. We labeled this factor Liberal Thinking (Malayang Pag-Iisip, in Filipino). We used the term liberal not only in the 
TABLE 1

Thinking Styles Inventory Scales: Means, Standard Deviations, and Alpha Coefficients $(N=429)$

\begin{tabular}{lllll}
\hline \hline Scale & \multicolumn{1}{c}{ Item } & $M$ & $S D$ & $\alpha$ \\
\hline Legislative & $5,10,14,32,49$ & 5.16 & 0.89 & 0.74 \\
Executive & $8,11,12,31,39$ & 5.09 & 0.87 & 0.74 \\
Judicial & $20,23,42,51,57$ & 5.17 & 0.76 & 0.76 \\
Global & $18,38,48,61$ & 4.87 & 0.84 & 0.67 \\
Local & $6,24,44,62$ & 4.70 & 0.85 & 0.61 \\
Liberal & $45,53,58,64,65$ & 4.94 & 0.91 & 0.81 \\
Conservative & $13,22,26,28,36$ & 4.73 & 1.10 & 0.54 \\
Hierarchic & $4,19,25,33,56$ & 5.09 & 1.08 & 0.62 \\
Monarchic & $43,50,54,60$ & 4.60 & 0.87 & 0.50 \\
Oligarchic & $27,29,30,52,59$ & 4.99 & 2.95 & 0.74 \\
Anarchic & $16,21,35,40,47$ & 5.10 & 0.82 & 0.65 \\
Internal & $9,15,37,55,63$ & 4.53 & 0.98 & 0.71 \\
External & $3,17,34,41,46$ & 5.37 & 0.99 & 0.81 \\
& & & & \\
\hline
\end{tabular}

sense of the liberal style (i.e., a preference for going beyond established rules and approaches) but also to mean not precise, inexact, loose, and free. Factor 1 describes people who prefer to work alone on unstructured tasks that require using novel problem-solving strategies and who attend to the various aspects of such tasks all at once without setting clear priorities.

For Factor 2, the highest loadings were from the Conservative, Executive, Monarchic, Local, Oligarchic, Judicial, and Hierarchic Scales. This factor was labeled Structured Thinking (or Maayos Na Pag-Iisip), because it represents a complex of styles that tend to adhere to structure. In particular, the factor describes a person who prefers to attend to one prestructured task at a time, focusing on details of the task according to a predefined approach. Unlike the style described by Liberal Thinking, in this approach a person is mindful of the other tasks at hand and completes them in order of priority.

Factor 3 received the highest positive loadings from the External and Oligarchic Scales and the highest negative loading from the Internal Scale. We labeled this factor Cooperative Thinking (Kooperatibang Pag-Iisip). It is descriptive of a person who prefers to collaborate with others while working on a variety of tasks simultaneously. The meaning of cooperative in this context is comparable to its economic meaning. Economic cooperatives are set up in communities to pool resources of small groups of people to more effectively meet the multiple requirements of economic development initiatives. Thus, the factor signifies more than the collaborative characteristic of the external style; it represents a preference for working with others for the purpose of uniting various cognitive resources of many people to address multiple tasks. 


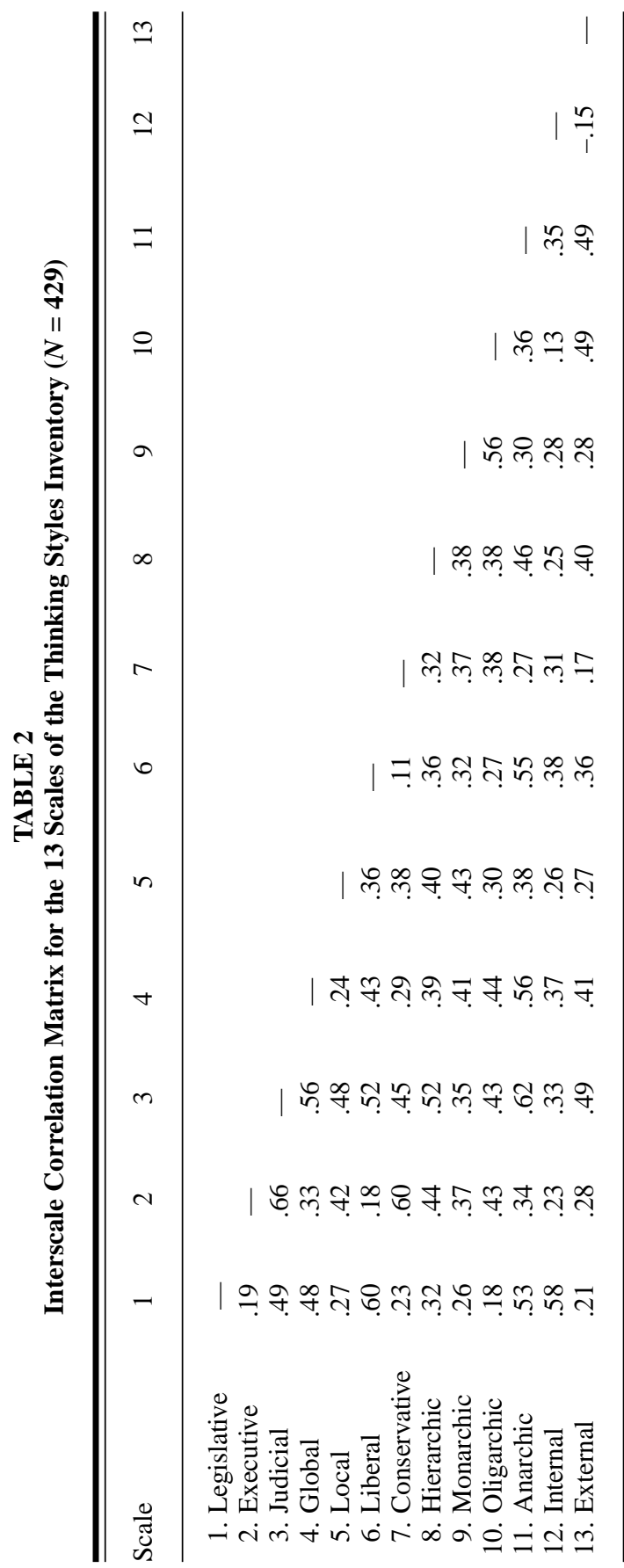


TABLE 3

Varimax-Rotated Three-Factor Model for the Thinking Styles Inventory

Scale

Factor 1

Factor 2

Factor 3

Legislative

Executive

Judicial

Global

Local

Liberal

Conservative

Hierarchic

Monarchic

Oligarchic

Anarchic

Internal

External

$\%$ of variance

Cumulative $\%$ of variance

Eigenvalue
.87

.51

.60

.77

.82

.55

.58

.83

.48

.61

.55

.67

.71

$-.46$

.87

42.7

42.7

5.55

12.1

9.9

54.8

64.7

1.57

1.29

\section{Correlations With Academic Achievement}

To investigate academic achievement in the Philippine context, we correlated the students' TSI scores with their GPAs. The correlations ranged from .00 to .17. Six scales were significantly correlated with GPA: Executive $(.17, p<.01)$, Judicial, Conservative, Hierarchic, Anarchic, and Internal (.12, .10, .11, .12, and .11 , respectively; all $\mathrm{ps}<.05) .{ }^{1}$ The first four scales loaded on Factor 2 , and the last two and the Judicial Scale loaded on Factor 1.

How do the results of this analysis compare with earlier findings? Grigorenko and Sternberg (1997) found that the judicial and legislative styles were positively related to a student's success in a variety of academic evaluation tasks, but they found that the executive style was more likely to be negatively correlated with success in these tasks. The results of the present study also revealed a relationship between the judicial style and general academic achievement, but we found

\footnotetext{
${ }^{1}$ The statistically significant correlations were all low, and this low range of correlations might be related to using the students' reported GPA as the measurement of achievement. Although it is conceivable that students' self-reports were unreliable and affected the robustness of the correlational analysis, this possibility seems unlikely because subsequent research using similar participants but obtaining the GPA from actual student records yielded correlations with the TSI scores in the same, and even slightly lower, range. It seems that for college students in the Philippines, achievement and GPA are not strongly correlated.
} 
no relationship between the legislative style and academic achievement. Moreover, in the present study the executive style was positively correlated with GPA. It should be noted, however, that Grigorenko and Sternberg's (1997) study involved gifted American students attending an elite institution of higher education. Zhang and Sternberg's (1998) study involving Hong Kong students of a wider range of abilities yielded results that were more consistent with those of the present study. The thinking styles that Zhang and Sternberg found to be positively associated with academic achievement were "the ones that require conformity (e.g., conservative), orientation toward a sense of order (e.g., hierarchic) and preference for working independently (e.g., internal)" (1998, p. 55). We found these same thinking styles to be correlated with academic achievement in a comparable Philippine sample. The significant correlations with the executive and judicial styles were consistent with the findings of the Hong Kong study, although the correlation between academic achievement and the anarchic style seems at odds. (However, one could argue that being able to exercise some degree of flexibility in prioritizing and executing tasks might help students complete academic requirements.)

\section{Discussion}

Our focus in this study was the viability of the TSI in assessing thinking styles among Filipino college students. We found internal consistencies of the 13 TSI Scales that were similar in magnitude to those found in earlier studies, and the intercorrelations among the scales were consistent with the predictions of the theory of mental self-government (Sternberg, 1988, 1997). The results of the factor analysis also yielded a factor structure that was consistent with the theory. Finally, the correlational analysis between the thinking styles and GPA revealed that certain thinking styles were related to academic achievement. Although the consistency of our results with the theory of mental self-government is important, the more significant contribution of the study relates to how certain results elaborate on specific assumptions of the theory.

In his theory of mental self-government, Sternberg (1997) argued that thinking styles are developed and socialized and that culture is one of the foremost factors that shape thinking styles. Sternberg indicated how different dimensions of culture may encourage or inhibit the development of specific styles. Thus, individuals in one culture, compared with those in other cultures, might be expected to have a higher or lower preference for certain styles.

The results of this study can be discussed within this general framework. In the introduction, we noted that different factors emerged from similar exploratory factor analyses conducted with American (Sternberg, 1994) and Hong Kong (Zhang \& Sachs, 1997) college students. However, the present study was not designed to test whether the factors that emerged were consistent with either of those factor structures (i.e., we did not do confirmatory factor analysis). It would 
be inappropriate, therefore, to interpret our results as verifying or disconfirming the other factor structures or as suggestive of a contrast between cultures. Instead, we should try to understand how the specific results of the study relate to the assumptions regarding sociocultural development of styles by looking at pertinent cultural concepts and practices.

Consider, for example, the items that loaded on Factor 3 (Cooperative Thinking or Kooperatibang Pag-Iisip). The factor received a high positive loading from the external items and a high negative loading from the internal items, showing the contrast between the two styles. Yet, the factor was also positively loaded with oligarchic items, suggesting that individuals who prefer to work with others when engaged in cognitive tasks (the external style) also prefer to work on several tasks at the same time without prioritizing them (the oligarchic style). The preference for working with other people seems to complement the abilities required in performing multiple tasks. Therefore, underlying this pattern of stylistic preferences, there is an element of cooperativism, which is a recurring concept in studies of Filipino personality. In particular, the concept and practice of bayanihan (togetherness in common effort; Elequin, 1974) is typically used to describe how Filipinos go out of their way to work together in concerted effort to extend assistance to relatives, neighbors, and even strangers. This practice is viewed as an expression of the Filipino concept of kapwa (shared identity and humanity; Enriquez, 1992). It is reasonable to assume that these cultural concepts and practices afford students the opportunity to draw from the cognitive resources of their peers as they attend to multiple tasks.

The configuration of thinking styles embodied in Factors 1 and 2, Liberal Thinking (Malayang Pag-Iisip) and Structured Thinking (Maayos Na Pag-Iisip), might correspond to ways of thinking that are developed in the Philippine school system. Malayang pag-iisip is akin to the inquiring attitude that schools seek to promote among their students. On the other hand, maayos na pag-iisip embodies the disciplined thought that schools try to instill. These two forms of thinking might be associated with tasks particular to different types of courses in the curriculum (e.g., the arts and humanities, on the one hand, and the sciences and mathematics, on the other). However, some researchers suggest that these two ways of thinking could be equally valued within the same types of courses. Bernardo (in press), for example, found that Filipino mathematics teachers advocated teaching practices aimed at developing both inquiry and disciplined thought, whereas, even at present, mathematics educators in the West tend to promote one over the other. Filipino teachers of science were found to hold similar beliefs (Bernardo, Clemeña, \& Prudente, 2000). On the basis of their beliefs about learning and teaching, it appears that Filipino teachers create learning environments that require their students to develop thinking processes that focus on trying out new and creative ways of thinking (malayang pag-iisip or liberal thinking) as well as more disciplined ways of thinking (maayos na pag-iisip or structured thinking). These contexts of learning demonstrate how preferences for configurations of learning styles might emerge. 
One may also see how learning styles relate to academic achievement within the Philippine educational context. Recall that 6 scales were correlated with GPA: Executive, Judicial, Conservative, Hierarchic, Anarchic, and Internal. The Executive, Conservative, Hierarchic, and Judicial Scales loaded on Factor 2, and the Anarchic, Internal, and Judicial Scales loaded on Factor 1. (Notice that the Judicial Scale loaded on both factors.) This pattern of correlation supports the notion that aspects of both ways of thinking are valued in the Filipino learning environment. Thus, thinking styles that are associated with both Factors 1 and 2 are related to achievement.

Although we did not intend this to be a comparative study, some differences may be observed between the pattern of correlations we found and the results of Grigorenko and Sternberg's (1997) study that involved American students. Recall for example, that the executive style was positively correlated with achievement for Filipino students, but the same style was negatively correlated with achievement for American students. Although the difference may have resulted from sampling, as previously noted, it may also be attributed to the prioritizing of thinking styles by the different educational systems. According to the theory of mental self-government, different cultures may value some thinking styles over others. Formal educational institutions tend to promote knowledge and skills that are valued by the larger culture or society within which they operate. Accordingly, educational systems in different cultures might also value and encourage different thinking styles. In this connection, the finding that one thinking style was positively correlated with achievement in one country, but negatively correlated in another, may reflect cultural preferences for thinking styles.

Researchers have found that within the Philippine educational system (e.g., Bernardo, 2000; Hornedo, Miralao, \& Santa Maria, 2000) there seems to be an emphasis on educational goals related to the attainment and mastery of prescribed and predefined knowledge, skills, and approaches to cognitive tasks. This emphasis is evident in the curricular prescriptions of such official documents as the Philippine Elementary Learning Competencies and the Philippine Secondary School Learning Competencies. Because the education system stresses the executive thinking style, it is not surprising to find a correlation between that style and academic achievement among Filipino students. Although we do not presume to have extensive knowledge of the American educational system, it seems plausible that the Philippine educational system places a higher priority on the executive thinking processes than does its American counterpart. By recognizing such differences in how educational institutions value some thinking styles over others, researchers may attain a better understanding of how thinking styles are related to school performance in different cultures.

In this discussion, we have attempted to link our specific pattern of results to Filipino cultural concepts and practices, particularly those related to Philippine schools. In doing so, we have drawn from the assumption of the theory of mental self-government (Sternberg, 1988, 1997) that cultural factors may influence 
how thinking styles develop in a sociocultural context. Our investigation involved a post hoc interpretation of results. In future studies, researchers should approach this topic more explicitly, by performing more systematic cross-cultural comparisons and by posing specific hypotheses regarding the nature of thinking styles and how thinking styles relate to the academic achievement of individuals in different cultures. Such studies will fine-tune the assumptions of Sternberg's (1988, 1997) theory and, of particular importance, clarify the sociocultural developmental processes that shape how different thinking styles become interrelated.

\section{REFERENCES}

Albaili, M. A. (1997). Differences among low-, average- and high-achieving college students on learning and study strategies. Educational Psychology, 17, 171-177.

Allport, G. (1937). Personality: A psychological interpretation. New York: Holt.

Bernardo, A. B. I. (2000). Frameworks and contents of Philippine basic education textbooks: A synthesis and exposition. In F. H. Hornedo, V. A. Miralao, \& F. P. Santa Maria (Eds.), The social and human sciences in Philippine basic education: A review of elementary and high school textbooks (pp. 1-24). Quezon City, Philippines: Philippine Social Science Council.

Bernardo, A. B. I. (in press). Filipino college math teachers' beliefs about learning and teaching: Reckoning with the school-mathematics and the inquiry-mathematics traditions. Learning Edge.

Bernardo, A. B. I., Clemeña, R. M. S., \& Prudente, M. S. P. (2000). The contexts and practices of science and mathematics education in the Philippines: Foundations of responsive science and mathematics teacher education programs. Manila, Philippines: Lasallian Institute for Development and Educational Research.

Biggs, J. B. (1989). Student's approaches to learning in Anglo-Chinese schools. Educational Research Journal, 4, 8-17.

Biggs, J. B. (1991). Approaches to learning in secondary and tertiary students in Hong Kong: Some comparative studies. Educational Research Journal, 6, 27-30.

Dunn, R., Beaudry, J. S., \& Klavas, A. (1989). Survey of research on learning styles. Educational Leadership, 46(6), 50-58.

Elequin, E. (1974). Educational goals, aims, and objectives (Tech. Rep. No. 114). Tokyo: National Institute for Educational Research, UNESCO-NIER Regional Programme for Educational Research in Asia.

Enriquez, V. G. (1992). From colonial to liberation psychology: The Philippine experience. Quezon City, Philippines: University of the Philippines Press.

Grigorenko, E., \& Sternberg, R. J. (1995). Thinking styles. In D. Saklofske \& M. Zeidner (Eds.), International handbook of personality and intelligence (pp. 205-230). New York: Plenum Press.

Grigorenko, E., \& Sternberg, R. J. (1997). Styles of thinking, abilities, and academic performance. Exceptional Children, 63, 295-312.

Helmke, A., \& van Aken, M. A. G. (1995). The causal ordering of academic achievement and self concept of ability during elementary school: A longitudinal study. Journal of Educational Psychology, 87, 624-637.

Hornedo, F. H., Miralao, V. A., \& Santa Maria, F. P. (Eds.). (2000). The social and human sciences in Philippine basic education: A review of elementary and high school textbooks. Quezon City, Philippines: Philippine Social Science Council. 
Kim, J., \& Michael, W. B. (1995). The relationship of creativity measures to school achievement and to preferred learning and thinking style in a sample of Korean high school students. Educational and Psychological Measurement, 55, 60-74.

Kwok, D. C., \& Lytton, H. (1996). Perceptions of mathematics ability versus actual mathematics performance: Canadian and Hong Kong children. British Journal of Educational Psychology, 66, 209-222.

Marsh, H. W., \& Yeung, A. S. (1997). Causal effects of academic self-concept on academic achievement: Structural equation models of longitudinal data. Journal of Educational Psychology, 89, 41-54.

Messick, S. (1994). The matter of style: Manifestations of personality in cognition, learning, and teaching. Educational Psychologist, 29, 121-136.

Pajares, F. (1996). Self-efficacy beliefs in academic settings. Review of Educational Research, 66, 543-578.

Pintrich, P. R., \& de Groot, A. V. (1990). Motivational and self-regulated learning components of classroom academic performance. Journal of Educational Psychology, 82, 33-40.

Rayner, S., \& Riding, R. J. (1997). Towards a categorisation of cognitive styles and learning styles. Educational Psychology, 17, 5-27.

Riding, R. J. (1997). On the nature of cognitive style. Educational Psychology, 17, 29-50.

Riding, R. J., \& Cheema, I. (1991). Cognitive styles-An overview and integration. Educational Psychology, 11, 193-215.

Schunk, D. H. (1991). Self-efficacy and academic motivation. Educational Psychologist, 26, 207-231.

Sternberg, R. J. (1988). Mental self-government: A theory of intellectual styles and their development. Human Development, 31, 197-224.

Sternberg, R. J. (1994). Thinking styles: Theory and assessment at the interface between intelligence and personality. In R. J. Sternberg \& P. Ruzgis (Eds.), Intelligence and personality (pp. 169-187). New York: Cambridge University Press.

Sternberg, R. J. (1997). Thinking styles. New York: Cambridge University Press.

Sternberg, R. J., \& Grigorenko, E. L. (1995). Styles of thinking in the school. European Journal for High Ability, 6, 201-219.

Sternberg, R. J., \& Grigorenko, E. L. (1997). Are cognitive styles still in style? American Psychologist, 52, 700-712.

Sternberg, R. J., \& Wagner, R. K. (1992). Thinking Styles Inventory. Unpublished test, Yale University, New Haven, CT.

Watkins, D. A. (1996). Learning theories and approaches to research: A cross-cultural perspective. In D. A. Watkins \& J. B. Biggs (Eds.), The Chinese learner: Cultural, psychological and contextual influences (pp. 3-24). Hong Kong: Comparative Education Research Centre and Melbourne: The Australian Council for Educational Research.

Witken, H. A., Oltman, P. K., Rasking, F., \& Karp, S. A. (1971). Embedded Figures Test, Children's Embedded Figures Test, Group Embedded Figures Test. Manual. Palo Alto, CA: Consulting Psychologists Press.

Zhang, L. F., \& Sachs, J. (1997). Assessing thinking styles in the theory of mental selfgovernment: A Hong Kong validity study. Psychological Reports, 81, 915-928.

Zhang, L. F., \& Sternberg, R. J. (1998). Thinking styles, abilities, and academic achievement among Hong Kong university students. Educational Research Journal, 13, 41-62.

Zimmerman, B. J. (1995). Self-efficacy and educational development. In A. Bandura (Ed.), Self-efficacy in changing societies (pp. 202-231). New York: Cambridge University Press. 


\section{APPENDIX \\ Sample Items for Each Scale of the Thinking Styles Inventory}

Thinking style

Description

Legislative

Executive

Judicial

Global

Local

Liberal

Conservative

Hierarchic

Monarchic

Oligarchic

Anarchic

Internal

External
When faced with a problem, I use my own ideas and strategies to solve it.

I like projects that have a clear structure and a set plan and goal.

I like to check and rate opposing points of view or conflicting ideas.

I like situations or tasks in which I am not concerned with details.

I prefer to deal with specific problems rather than with general questions.

I enjoy working on projects that allow me to try novel ways of doing things.

I like to do things in ways that have been used in the past.

I like to set priorities for the things I need to do before I start doing them.

When I try to finish a task, I tend to ignore problems that come up.

Usually when working on a project, I tend to view almost all aspects of it as equally important.

When I have many things to do, I do whatever occurs to me first.

When faced with a problem, I like to work it out by myself.

When starting a task, I like to brainstorm ideas with friends or peers. 
